\title{
Culturally Responsive Positive Behavior Supports: Considerations for Practice
}

\author{
Tachelle Banks ${ }^{1}$, Festus E. Obiakor ${ }^{2}$ \\ ${ }^{1}$ Department of Teacher Education, Cleveland State University, Cleveland, OH, USA \\ ${ }^{2}$ Department of Early Childhood and Special Education, Valdosta State University, Valdosta, GA, USA \\ Correspondence: Tachelle Banks, Department of Teacher Education, Cleveland State University, 2121 Euclid Ave, JH \\ 304, Cleveland, OH, 44115, USA. Tel: 216-687-4608.
}

Received: January 16, 2015 Accepted: January 29, 2015 Online Published: February 12, 2015

doi:10.11114/jets.v3i2.636

URL: http://dx.doi.org/10.11114/jets.v3i2.636

\begin{abstract}
Classrooms are not culturally neutral terrains, but rather are constructed around sets of norms, values, and expected behaviors that are culturally bound. Low tolerance levels and expectations are an indication of the incongruence between the education strategies utilized by teachers and the cultural and linguistic differences of students that are served in an educational system in which they are required to perform based on standards that are not similar to their own. Combining Positive Behavior Intervention Supports (PBIS) with cultural and linguistic variables will help to enhance positive behavior of culturally and linguistically diverse (CLD) students. This paper describes Culturally Responsive Positive Behavior Intervention Supports (CRPBIS) as a system that specifically acknowledges the presence of CLD students and the need for them to find relevant connections among themselves and with the behavioral goals and objectives that schools ask them to perform. Suggestions are offered that support the infusion of culturally responsive practices throughout the implementation of PBIS.
\end{abstract}

Keywords: culturally responsive positive behavior intervention supports, CLD students

\section{Introduction}

Eastwood School has a population of 324 students, a 95\% poverty rate, and sits in the center of a large metropolitan area. Like many other schools across the country, Eastwood has had problems dealing with myriad behavior problems that affect classroom learning and school culture. After trying out other school-wide behavior management techniques that did not work for staff and students, they decided to implement School-wide Positive Behavior Intervention Supports (SW-PBIS). To solidify the institution of SW-PBIS, a team of 60 Eastwood staff members participated in a three-day training on SW-PBIS to reduce office discipline referrals (ODRs) by 20-60\%, decrease inappropriate behaviors, and increase appropriate behaviors. The Eastwood team learned how to develop capacity by successfully implementing the characteristics of SW-PBIS that included (a) using data-based decision making, (b) developing a simple set of behavioral expectations, (c) teaching behavioral expectations, and (d) acknowledging appropriate behaviors. While these strategies ensured that behavioral expectations were standardized for all students enrolled at Eastwood, they did not take into account cultural and linguistic diversities amongst the student population. In other words, the strategies did not take into account teacher cultural competence (or lack thereof) and the role that teachers play in supporting all students to better meet behavioral expectations in a classroom. Before long, Eastwood staff members asked for more in-service training on how to infuse culturally responsive strategies into their SW-PBIS training. In the end, they did the training and found that in order to minimize the continual marginalization of culturally and linguistically diverse (CLD) students in universal tiered models, culturally responsive strategies needed to be integrated into the SW-PBIS model.

\section{Contextual Frameworks}

Considering the above case of the Eastwood School, it is apparent that addressing socio-behavioral needs of children in school is a worthwhile societal investment. While there are many techniques out there, the application of Positive Behavior Intervention Supports (PBIS) sets the stage for improving school safety and climate within school districts, campuses, and classrooms. It is common knowledge that classrooms are not culturally neutral terrains; they are constructed around sets of norms, values, and expected behaviors that are culturally bound. Though zero-tolerance 
perspectives are adopted by many schools, they sometimes indicate incongruences between education strategies utilized by teachers and cultural and linguistic differences that students bring to schools. As a result, combining PBIS with cultural and linguistic variables helps to enhance positive behaviors of CLD students. In this article, we discuss how Culturally Responsive Positive Behavior Intervention Supports (CRPBIS) can be used to enhance positive behaviors of CLD students in schools and classrooms.

\subsection{The Use of Culturally Responsive Practices on CLD Students}

The overrepresentation of CLD students in suspensions and expulsions, ODRs, and corporal punishment has been well documented (Raffaele-Mendez \& Knoff, 2003; Skiba, Michael, Nardo, \& Peterson, 2002; Wald \& Losen, 2003). Research suggests that differential expectations between the home and school lives of these students may contribute to disciplinary disproportionality (Cartledge, Tillman, \& Talbert-Johnson, 2001; Neal, McCray, Webb-Johnson, \& Bridgest, 2003; Perry, Steele, \& Hilliard, 2003; Skiba et al., 2002; Townsend, 2000, 2002). Classrooms are not culturally neutral terrains, but rather are constructed around sets of norms, values, and expected behaviors that are culturally bound. Likewise, students bring into the classroom a host of culturally bound expectations about learning and behavior. Classroom norms and expectations often align with White middle-class values and orientations such as individual praise (Lerman, 2000), competition (Boykin, Tyler, \& Miller, 2005; Gay, 2000), individualism (Boykin et al., 2005), and linear thinking and communication patterns (Hale-Benson, 1986; Swartz, 2004).

Culturally responsive practices involve utilizing the cultural knowledge, life experiences, and learning styles of CLD students to make learning more relevant and effective for them (Obiakor, 2008). By building upon the knowledge and strengths students bring with them from their homes and communities, culturally responsive practice validates who they are and sets high expectations for behavior and learning. It comprehensively creates an environment where diversity is affirmed and establishes a cultural lens for determining normative behavior and learning expectations (Gay, 2000; King, 2004; Nieto, 2004). Typically, PBIS involves individualized and sustained decision-making, planning, and problem solving, which are intertwined with instructional foci directed toward behavioral expectations. Combining PBIS with cultural and linguistic variables will help to enhance positive behavior of CLD students.

\section{PBIS: The Model}

In 2001, the United States Surgeon General published a report on the status of adolescents and antisocial behavior in which it was reported that schools can expect an increasing number of serious problem behaviors if antisocial peer networks are allowed to be established inside schools and deviant youth behavior is reinforced by peers and adults. To affect the rates and prevent the development of antisocial behavior in youth, the Surgeon General report strongly suggests that a prevention-based approach be emphasized. It also suggests that contingencies be arranged so an intolerant attitude toward antisocial behavior is established, antisocial networks are actively broken up and monitored, schools provide parents with strategies to increase their efficiency and effectiveness in the home, a commitment to school is enhanced, academic success is increased, a positive school climate is created and fostered, and individual social skills and competence are taught and encouraged across all students.

\subsection{Understanding the Importance of PBIS on Student Behaviors}

The application of PBIS aims to improve school safety and climate within districts and campuses. The PBIS approach is a school-wide prevention and intervention model that proactively improves school behavior issues. This approach has been successful, in part, due to its whole-school focus. Difficult behavioral issues that impact climate and safety, such as bullying and aggression, have proven difficult to remedy through small-scale interventions limited to a single classroom or subset of students.

To a large measure, PBIS is based on the notion that effective behavior change must not only reduce inappropriate behaviors, but also must teach suitable alternatives. Behavior changes should not only help the child in the immediate environment, or the short-term; they must also be important for their life after school, or the long-term. The key concept of PBIS is to change a problem behavior; it is first necessary to remediate deficient contexts related to behavior repertoires or environmental conditions. Behavior repertoire refers to lack of competency in a given behavior skill set or a combination of behavior skill sets. This means that a student does not have the necessary behaviors to be successful in a given environment. In this instance, students can be taught behavioral skills to increase the likelihood of success in a classroom environment. Communication, social, and self-management skills are all necessary to meet the demands of day-to-day existence in school, at home, or in the community. Environmental conditions refer to stimuli in any particular environment, which are not conducive to appropriate behavior for an individual and contribute to the emergence of problematic behaviors. In the end, PBIS tries to change the environment so that the conditions for appropriate behavior and its reinforcement are available, as well as to teach appropriate behaviors as a substitute for accessing reinforcement in the environment. 


\section{From Traditional Teacher Beliefs to Culturally Sensitive Pedagogical Obligations}

\subsection{The Impact of Teachers' Beliefs and Biases on CLD Students}

While the percentages used in the PBIS model to address student needs are based on theoretical assumptions that most students will respond to evidence-based practices, what it does not take into account is that a teacher's professional judgment plays a key role in the academic trajectory of the child (Algozzine, Ysseldyke, \& Christiansen, 1983; Beswick, Willms, \& Sloat, 2005; Leiter \& Brown, 1985). The student population is more diverse than the teacher population, which mostly consists of White, middle-class women (Cartledge, Singh, \& Gibson, 2008). For example, Good and Nichols (2001) contended that teacher beliefs and behaviors relate to student performance. They also reported studies that show African American students receiving lower teacher evaluations than White students despite higher test scores, as well as studies indicating that African American students, especially males, receive lowered academic scores because of classroom conduct. Students who are cooperative are predicted to have academic achievement, while students who are not cooperative are predicted to have poor academic performance (Cartledge et al., 2008). Sanchez-Fowler, Banks, Anhalt, Devore, and Kalis (2009) found that White teachers rated more children as highly externalizing and less prosocial, whereas African American teachers rated more children as highly externalizing and highly prosocial. The researchers suggested that African American teachers in the study were more culturally aligned to the interpretations of African American student behavior than were their White counterparts. In addition, teachers of students with disabilities are characterized as having low expectations and negative attitudes toward these students, expecting these students to present problem behaviors, and typically attributing the lack of progress to the students (Gay, 2000, 2002; Noguera, 2003).

\subsubsection{Need for Social-Skill Instruction}

Behavioral nonconformity is one of the primary reasons that many students are referred to special education (Cartledge et al., 2008). The authors stated that if children and youth are not taught how to meet behavioral expectations in classroom environments, then behavioral delinquency is likely to persist. As a result, social-skill instruction should relate to the students' cultures and instructors of social skills should know the differences between different cultures. When teachers begin to learn about the culture of their students, they begin to understand more about their students, as well as about themselves, especially in regards to their personal biases.

\subsubsection{Low Tolerance and Expectations}

Low tolerance levels and expectations are an indication of the incongruence between the education strategies utilized by teachers and the cultural and linguistic differences of students that are served in an educational system in which they are required to perform based on standards that are not similar to their own. Moreover, lack of tolerance of differences adversely impacts teachers' perceptions of the students that they serve in spite of the application of evidence-based practices, including universal tiered intervention models (Delpit, 1992; Ladson-Billings, 1994). What is needed is an adaptation of the tiered models to better address the needs of all students, including CLD students.

\subsection{CRPBIS: Improving Teacher Practices Instead of Blaming Student Behaviors}

CRPBIS is a system that specifically acknowledges the presence of CLD students and the need for them to find relevant connections among themselves and with the behavioral goals and objectives that schools ask them to perform. CRPBIS considers the valuation, consideration, and integration of individuals' culture, language, heritage, and experiences leading to facilitated learning and development (Klingner et al., 2005). As a result, school-wide behavior supports should be proactive and promote a positive, culturally responsive climate that is conducive to learning by all. Clearly, educators and service providers understand that perceptions of behavioral appropriateness are colored by cultural expectations or by what is perceived as inappropriate across cultures (Obiakor, 2008, 2012). Unlike traditional behavior management which views the individual as the sole problem and seeks to "fix" him or her by quickly eliminating the challenging behavior, CRPBIS views such things as settings and lack of skill as parts of the "problem" and works to change them.

Vincent, Randall, Cartledge, Tobin, and Swain-Bradway (2011) deconstructed the theoretical foundations of SW-PBIS and cultural responsiveness to find their common denominator. SW-PBIS depends on evidence-based practices as a way to support student behavior. Culturally responsive educational practices can help support student behavior by

1. Enhancing staff members' cultural knowledge, in which they learn about cultural dimensions such as expressiveness, interactions between generations, and language;

2. Enhancing staff members' cultural self-awareness, since they will better understand other people's cultures once they understand their own culture first;

3. Validating other peoples' cultures, in which students' cultural identity is acknowledged rather than "color blinded";

4. Increasing cultural relevance, in which students appropriately question discipline practices they deem unfair; 
5. Establishing cultural validity, in which inappropriate behaviors are defined to minimize teacher judgment; and

6. Emphasizing cultural equity, in which differences are acknowledged and accommodated.

For example, social skills instruction must be in the language of students' cultural backgrounds as well as modeled as appropriate behaviors desired by the teacher. In addition, the authors state that to improve the SW-PBIS research agenda, more attention should be paid to student discipline outcomes disaggregated by race so that the disciplinary disproportionality can be reduced. The following are needed: (a) observation of disciplinary disproportionality in relation to SW-PBIS implementation; (b) critical observation of how much existing training materials and evaluation tools address cultural responsiveness; and (c) permission for the voices of CLD staff, students, and parents to be heard. SW-PBIS implementation must support students, staff, decision making, and students' social and academic success.

\subsubsection{Using Interventions to Improve Behavioral and Instructional Practices}

Educational leaders have realized that true educational reform begins with focusing on systemic change for behavioral and instructional systems. SW-PBIS and Response to Intervention (RtI) both use scientifically validated behavioral and instructional support practices that are data driven. Pry and Cheesman (2010) reflected on the need for implementation of culturally responsive teaching (CRT) into SW-PBIS and RtI models. The authors argued that teachers are the primary agents of change, as teacher behavior contributes to the behavioral and academic challenges in the classroom. For example, SW-PBIS uses four interrelated systems that implement the following descriptors: (a) school-wide, which includes all students, staff, and settings; (b) classroom, which is the main place where academic instruction occurs; (c) non-classroom, which is less structured areas of the school (e.g., hallways); and (d) individual student, which focuses on students that have demanding individualized behavioral support needs. SW-PBIS prefers to use the word "support" over "manage" since support suggests that actions are proactive rather than reactive. Experienced teachers ensure success by combining behavioral and instructional supports.

Juxtapose with the SW-PBIS interrelated system, Ladson-Billings (1995) stated that CRT is needed to (a) promote the academic abilities of all students, (b) encourage and sustain cultural competence, and (c) develop "sociopolitical" or critical consciousness. Pry and Cheesman (2010) discussed the guiding principles of SW-PBIS in relation to CRT, which allowed for the integration of behavioral and instructional supports. The principles include:

1. Effective teaching is culturally responsive, in which teachers commit to know their students academically and culturally to better understand the teaching/learning dynamic;

2. Teach respect to model caring, so that relationships are promoted and teaching/learning is facilitated; and

3. Problem resolution, not problem students, in which the problems are examined at the school level rather than at the student level.

\section{2. 2 Understanding the Need for Culturally Relevant Interventions}

Although implementation of systems change may be difficult due to social dominance and hegemony, there are still many reasons for why this implementation needs to occur for culturally responsive behavioral and instructional support strategies. Harris-Murri, King, and Rostenberg (2006) contended that if the RtI model does not consider CLD students, then these students are still at risk of having their behaviors and emotional well-beings misunderstood as disordered. The authors discussed the need for culturally responsive RtI as a way to reduce disproportionate minority representation of emotional disturbance (ED) in the Individuals with Disabilities Education Act (IDEA) (2004) eligibility category.

Considering sociocultural factors that influence students' behavior is necessary (Harris-Murri et al., 2006). Sociocultural factors include teachers' biases and backgrounds, students' cultural and linguistic backgrounds, and societal and institutional factors impacting students' opportunities and interpersonal relationships. Harris-Murri et al. (2006) defined culturally responsive classroom practices and instruction as strategies that recognize the presence of CLD students and the necessity for these students to find relevant connections between their culture and the subject matter being taught. Moreover, RtI must expand the scope of the defined problem to include other factors related to student learning and behavior, such as knowledge, culture and language, teacher perception, and school factors as obstacles for student development. Finally, the RtI team must understand why students are being referred to special education, which is usually due to teacher perceptions of student behavior as problematic (Harris-Murri et al., 2006).

\subsection{Summary and Emphasis on the Importance of CRPBIS}

In sum, PBIS is characterized as a long-term approach to reducing problematic behavior by teaching behavior that is better suited to the given setting and provides the contextual supports necessary for successful outcomes (ERIC, 1999). In conjunction with CRT, CRPBIS includes evidence-based practices designed to foster progressive development of academic, behavior, and cultural competencies in all students. Figure 1 illustrates the whole-school focus intended by CRPBIS and that culturally responsive practices are integrated at all levels of prevention. 

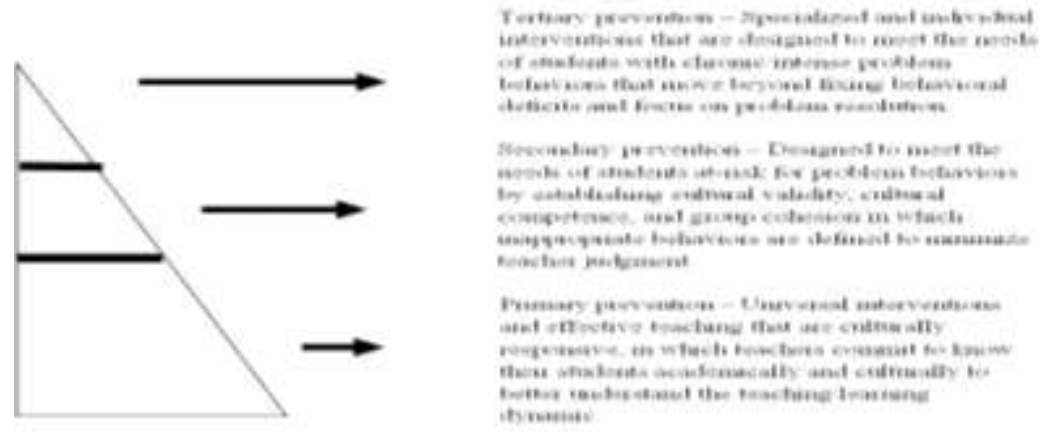

Figure 1. CRPBIS Model

The model breaks down the focus of whole-school interventions into three categories. The tertiary prevention tier consists of the smallest number of students who have chronic/intense problem behaviors that are not common among all students within the school. The secondary prevention tier consists of the students who are at-risk for problem behaviors. This group of students is larger in number than the tertiary prevention group, but smaller than the primary prevention group, which is the prevention tier including all students within the school. The general interventions within this tier are applied to every student and focus on a broad set of concepts to improve teaching and learning.

In essence, the aforementioned CRPBIS strategies create the social culture of the school. In acknowledging that gaps between school and home behavior expectations for students may exist, culturally responsive strategies must consider both students' home culture and the culture of the school. In addition, recognizing that behavioral norms are location specific, the development and teaching of behavioral expectations must clearly delineate and teach expectations for school behaviors while also validating the cultural expectations and ways of being that students bring with them from their homes and communities. This involves incorporating cultural knowledge from students and their families in the development of a school-wide plan and, at times, adjusting school expectations to more closely reflect the values and ways of being present within the school community. Further, teams need to support staff in reflecting upon the ways in which their cultural perspectives affect classroom instruction, as well as classroom and school-wide behavioral management. Culturally bound expectations in the classroom and school need to be recognized and acknowledged so that practices can be modified to be culturally responsive and ensure all students are benefitting equally from school and classroom environments, regardless of gender, ethnicity, socioeconomic status, or disability status. Finally, behavioral interventions must be considered through a culturally responsive lens to ensure that student needs are being addressed and met in a culturally competent manner.

\section{Future Perspectives}

Noguera (2003) contended that schools for many CLD students, especially those with the greatest needs, focus so much on behavior control and dispensing punitive consequences that educators fail to realize that these administrative actions are counterproductive and lead students to reject the standards of the school. The critical narrative of PBIS is that, while the percentages used in the tiered models to address student needs are based on theoretical assumptions that most students will respond to evidence-based practices, the model does not take into account the professional judgment of the teacher or decisions made by the teacher that play a key role in the academic trajectory of the child and subsequent need of special education services (Algozzine et al., 1983; Beswick et al., 2005; Leiter \& Brown, 1985). For example, educators are more likely to suspend or expel students who demonstrate problematic behaviors or give them more restrictive classroom placements (Lo \& Cartledge, 2007; Skiba et al., 2002; Skiba, Poloni-Staudinger, Gallini, Simmons, \& Feggins-Azziz, 2006; Skiba et al., 2008). African American children, in particular, receive more disciplinary actions with harsher penalties than White students (Skiba et al., 2002; Verdugo, 2002). These harsh punishments are unproductive and relate more consistently than any other factor to special education disproportionality (Skiba et al., 2002; Skiba, Poloni-Staudinger, Simmons, Feggins-Azziz, \& Chung, 2005). Moreover, the PBIS model does not explicitly state that as a result of disproportionality of CLD students receiving special education services, most of the students receiving tertiary interventions have continual negative school experiences.

\subsection{Implementing Appropriate Tiered Interventions for CLD Students}

When deciding whether a practice is appropriate for implementation as part of a tiered intervention model, the practice must be validated with students with whom the interventions will be used. The PBIS model is a promising practice when used with CLD students. Before determining whether a strategy is evidence-based for these students, the research must clearly disaggregate CLD variables as well as additional contextual variables (Klingner \& Bianco, 2006). In 
addition, children identified as English language learners (ELLs) are often not included in research samples because of their limited English proficiency, which results in limited external validity. As a result, prescribed strategies may not be appropriate for CLD students (Klingner \& Edwards, 2006). To address the omission of the cultural relevance of the tiered behavior model, culturally responsive practices must be integrated in such a way that culture is not a static set of characteristics located within individuals (e.g., ethnicity and social class), but rather as instrumental and indexed in practice (Gutierrez \& Rogoff, 2003). Incorporating culturally responsive practice into the PBIS framework means that both district and school level administrators are actively committed to addressing racial/ethnic, socioeconomic, and ability status disparities in ODR; suspension/expulsion rates; and where educators use their understanding of the experiences lived by students in the design of interventions (Dupper \& Bosch, 1996). This active commitment means allowing sufficient time and planning for professional development to enhance staff members' self- and cultural-awareness to increase the use of culturally responsive practices. Further, the district and school must make an open commitment to ensure all families feel welcome and included in the development of the framework and implementation process.

On the whole, CRPBIS does not involve augmenting PBIS with culturally responsive practices in an additive manner. Rather, CRPBIS must involve the infusion of culturally responsive practices throughout the implementation of PBIS. CRPBIS enhances the behavioral practices within a school environment by (a) minimizing cultural mismatches in behavioral expectations, (b) creating a cultural lens for viewing behavioral norms, and (c) affirming the diversity found within the school environment. District- and school-level administrators must make the commitment to address issues of equity in order for CRPBIS implementation to be successful. Culturally responsive practices are infused throughout each of the components of school-wide CRPBIS implementation by ensuring families' and students' cultural practices are represented and incorporated when developing school-wide norms, lessons, and reinforcement systems. Further, CRPBIS schools examine and disaggregate disciplinary data by subgroup (i.e., ethnicity, socioeconomic status, and disability status) to examine potential disproportionality in ODRs and modify practices, as needed, with the goal of equally benefitting all student groups. Armed with this knowledge, general and special educators must examine their current school practices to determine if these practices are accurately reflecting the needs of their CLD students and families.

\section{Conclusion}

Meeting the needs of students who are different requires professionals who think differently about service provision. Professionals who think differently about their profession and service provision understand the notion of being servant leaders, contributors, and change agents to positively impact the lives of families and children. In a CRPBIS system, cultural and linguistic differences are not variables in problematic behavior. Cultural and linguistic differences are part of the solution and not the deficit. A CRPBIS system will enhance students' behavioral development by constructing a learning environment that reflects their cultural membership in the class and throughout the school. To that end, schools must go beyond school slogans in developing a proactive environment. Teachers and service providers must attend to all students' behavioral needs, try to incorporate these needs into classroom daily routines, and avoid punitive measures that are counterproductive. Finally, going back to the exemplary model provided by the Eastwood School in the introductory case, it is important that schools know their strengths and weaknesses. We believe schools must work with communities to examine issues related to classroom discipline, cultural and linguistic differences, and pedagogical practices to further develop successful approaches for building positive behavioral skills.

\section{References}

Algozzine, B., Ysseldyke, J. E., \& Christiansen, S. (1983). An analysis of the incidence of special education placement: The masses are burgeoning. Journal of Special Education, 17(2), 141-147. http://dx.doi.org/10.1177/002246698301700205

Beswick, J. F., Willms, J. D., \& Sloat, E. A. (2005). A comparative study of teacher ratings of emergent literacy skills and student performance on a standardized measure. Education Journal, 136(1), 116-137.

Boykin, A. W., Tyler, K. M., \& Miller, O. A. (2005). In search of cultural themes and their expressions in the dynamics of classroom life. Urban Education, 40(5), 521-549. http://dx.doi.org/10.1177/0042085905278179

Cartledge, G., Singh, A., \& Gibson, L. (2008). Practical-behavior management techniques to close the accessibility gap for students who are culturally and linguistically diverse. Preventing School Failure, 52(3), 29-38. http://dx.doi.org/10.3200/PSFL.52.3.29-38

Cartledge, G., Tillman, L., \& Talbert, J. C. (2001). Professional ethics within the context of student discipline and diversity. Teacher Education and Special Education, 24(1), 25-37. http://dx.doi.org/10.1177/088840640102400105 
Delpit, L. D. (1992). Education in a multicultural society: Our future's greatest challenge. Journal of Negro Education, 61(3), 237-249. http://dx.doi.org/10.2307/2295245

Dupper, D. R., \& Bosch, L. A. (1996). Reasons for school suspensions: An examination of data from one school district and recommendations for reducing suspensions. Journal for a Just and Caring Education, 2(2), 140-150.

ERIC. (1999). Positive behavior support and functional assessment: ERIC/OSEP Digest E580. Retrieved from http://www.ericdigests.org/2000-2/positive.htm

Gay, G. (2000). Culturally responsive teaching: Theory, research, and practice. New York: Teachers College Press.

Gay, G. (2002). Preparing for culturally responsive teaching. Journal of Teacher Education, 53(2), 106-116. http://dx.doi.org/10.1177/0022487102053002003

Good, T., \& Nichols, S. L. (2001). Expectancy effects in the classroom: A special focus on improving the reading performance of minority students in first-grade classrooms. Educational Psychologist, 36(2), 113-126. http://dx.doi.org/10.1207/S15326985EP3602_6

Gutierrez, K. D., \& Rogoff, B. (2003). Cultural ways of learning: Individual traits or repertoires of practice. Educational Researcher, 32(5), 19-25. http://dx.doi.org/10.3102/0013189X032005019

Hale-Benson, J. (1986). Black children: Their roots, culture, and learning styles $\left(2^{\text {nd }}\right.$ ed.). Baltimore: Johns Hopkins University Press.

Harris, M. N., King, K., \& Rostenberg, D. (2006). Reducing disproportionate minority representation in special education programs for students with emotional disturbances: Toward a culturally responsive response to intervention model. Education \& Treatment of Children (West Virginia University Press), 29(4), 779-799.

Individuals with Disabilities Education Act of 2004, Pub. L. No. 108-446, § 101, 118 Stat. 2647 (2004).

King, K. P. (2004). Both sides now: Examining transformational learning and professional development. Innovative Higher Education, 29(2), 153-172. http://dx.doi.org/10.1023/B:IHIE.0000048796.60390.5f

Klingner, J., \& Bianco, M. (2006). What is special about special education for culturally and linguistically diverse students with disabilities? In B. Cook \& B. Schirmer (Eds.), What is special about special education? (pp. 37-53). Austin, TX: PRO-ED.

Klingner, J. K., Artiles, A. J., Kozleski, E., Harry, B., Zion, S., Tate, W., \& Riley, D. (2005). Addressing the disproportionate representation of culturally and linguistically diverse students in special education through culturally responsive educational systems. Education Policy Analysis Archives, 13(38), 1-43. http://dx.doi.org/10.14507/epaa.v13n38.2005

Klingner, J. K., \& Edwards, P. (2006). Cultural consideration with response-to-intervention model. Readings Research Quarterly, 41(1), 108-117. http://dx.doi.org/10.1598/RRQ.41.1.6

Ladson-Billings, G. (1994). The dreamkeepers: Successful teaching for African-American students. San Francisco: Jossey-Bass.

Ladson-Billings, G. (1995). Toward a theory of culturally relevant pedagogy. American Educational Research Journal, 32(3), 465-491. http://dx.doi.org/10.3102/00028312032003465

Leiter, J., \& Brown, J. S. (1985). Determinants of elementary school grading. Sociology of Education, 58(3), 166-180. http://dx.doi.org/10.2307/2112417

Lerman, S. (2000). The social turn in mathematics education research. In J. Boaler (Ed.), Multiple perspectives on mathematics teaching and learning (pp. 19-44). Westport, CT: Ablex.

Lo, Y., \& Cartledge, G. (2007). Office disciplinary referrals in an urban elementary school. Multicultural Learning and Teaching, 2(1), 20-38. http://dx.doi.org/10.2202/2161-2412.1014

Neal, L. I., McCray, A. D., Webb-Johnson, G., \& Bridgest, S. T. (2003). The effects of African American movement styles on teachers' perceptions and reactions. Journal of Special Education, 37(1), 49-57. http:dx.doi.org/10.1177/00224669030370010501

Nieto, S. (2004). Affirming diversity: The sociopolitical context of multicultural education. Boston: Pearson.

Noguera, P. A. (2003). Schools, prisons, and the social implications of punishment: Rethinking disciplinary practices. Theory Into Practice, 42(4), 341-350. http://dx.doi.org/10.1207/s15430421tip4204_12

Obiakor, F. E. (2008). The eight-step approach to multicultural learning and teaching ( $3^{\text {rd }}$ ed.). Dubuque, IA: Kendall Hunt. 
Obiakor, F. E. (2012). Hobson's choice: Illusory intervention choice for culturally and linguistically diverse learners with problem behaviors. In J. P. Bakken, F. E. Obiakor, \& A. F. Rotatori (Eds.), Behavior disorders: Identification, assessment, and instruction of students with EBD: Advances in special education 22 (pp. 221-231). Bingley, United Kingdom: Emerald. http://dx.doi.org/10.1108/S0270-4013(2012)0000022013

Perry, T., Steele, C., \& Hilliard, A. III (2003). Young, gifted, and black: Promoting high achievement among African-American students. Boston: Beacon Press.

Pry, R. D., \& Cheesman, E. (2010). Reflections on culturally responsive teaching: Embedding theory into practices of instructional and behavioral support. Journal of Praxis in Multicultural Education, 5(1), 36-51. http:dx.doi.org/10.9741/2161-2978.1031

Raffaele-Mendez, L. M., \& Knoff, H. M. (2003). Who gets suspended from school and why: A demographic analysis of schools and disciplinary infractions in a large school district. Education and Treatment of Children, 26(1), 30-51.

Sanchez-Fowler, L. T., Banks, T., Anhalt, K., Devore, H. H., \& Kalis, T. (2009). The association between externalizing behavior problems, teacher-student relationship quality, and academic performance in young urban learners. Behavioral Disorders, 33(3), 167-183.

Skiba, R. J., Michael, R. S., Nardo, A. C., \& Peterson, R. (2002). The color of discipline: Sources of racial and gender disproportionality in school punishment. Urban Review, 34(4), 317-342. http://dx.doi.org/10.1023/A:1021320817372

Skiba, R. J., Poloni-Staudinger, L., Gallini, S., Simmons, A. B., \& Feggins-Azziz, L. R. (2006). Disparate access: The disproportionality of African American students with disabilities across educational environments. Exceptional Children, 72(4), 411-424. http://dx.doi.org/10.1177/001440290607200402

Skiba, R. J., Poloni-Staudinger, L., Simmons, A. B., Feggins, L. R., \& Chung, C. G. (2005). Unproven links: Can poverty explain ethnic disproportionality in special education? The Journal of Special Education, 39(3), 130-144. http://dx.doi.org/10.1177/00224669050390030101

Skiba, R. J., Simmons, A. D., Ritter, S., Gibb, A., Rausch, M. K., Cuadrado, J., \& Chung, C. G. (2008). Achieving equity in special education: History, status, and current challenges. Exceptional Children, 74(3), 264-288. http://dx.doi.org/10.1177/001440290807400301

Swartz, E. (2004). Casing the self: A study of pedagogy and critical thinking. Teacher Development, 8(1), 45-65. http://dx.doi.org/10.1080/13664530400200213

Townsend, B. (2000). The disproportionate discipline of African American learners: Reducing school suspension and expulsions. Exceptional Children, 66(3), 381-391. http://dx.doi.org/10.1177/001440290006600308

Townsend, B. (2002). "Testing while black": Standards-based school reform and African American learners. Remedial and Special Education, 23(4), 222-230. http://dx.doi.org/10.1177/07419325020230040501

Verdugo, R. R. (2002). Race-ethnicity, social class, and zero-tolerance policies: The cultural and structural wars. Education and Urban Society, 35(1), 50-75. http://dx.doi.org/10.1177/001312402237214

Vincent, C. G., Randall, C., Cartledge, G., Tobin, T. J., \& Swain-Bradway, J. (2011). Toward a conceptual integration of cultural responsiveness and schoolwide and positive behavior support. Journal of Positive Behavior Interventions, 13(4), 219-229. http://dx.doi.org/10.1177/1098300711399765

Wald, J., \& Losen, D. J. (2003). Defining and redirecting a school-to-prison pipeline. In J. Wald \& D. J. Losen (Eds.), New directions for youth development (No. 99; Deconstructing the school-to-prison pipeline) (pp. 9-15). San Francisco: Jossey-Bass. http://dx.doi.org/10.1002/yd.51

\section{(cc) $\mathrm{BY}$}

This work is licensed under a Creative Commons Attribution 3.0 License. 